\title{
SARM
}

SAFETY ANALYSIS AND RISK MANAGEMENT

\author{
KEY WORDS: \\ COMPUTER CODE \\ SAFETY \\ PRA
}

RETENTION PERIOD:

LIFETIME

\section{CERTIFICATION PLAN FOR SAFETY AND PRA CODES(U)}

\author{
By \\ H. Toffer \\ R. D. Crowe \\ Westinghouse Hanford Company
}

\author{
M. J. Ades \\ Reactor Safety Division \\ Savannah River Laboratory
}

ISSUED: MAY 1990

SRL SAVANNAH RIVER LABORATORY, AIKEN, SC 29808

Westinghouse Savannah River Company

Prepared for the U. S. Department of Energy under

Contract DE-AC09-89SR 18035

$$
\begin{array}{ccc}
4 & 4 \\
4 & 4 & 4 \\
4 & 4
\end{array}
$$


PROJECT: Code Certification

DOCUMENT: WSRC-TR-90-183

TITLE: Certification Plan for Safety and PRA Codes

TASK:

APPROVALS

M. J. Hitchler, Manager Reactor Safety Research

L.A. Wooten, Manager Safety Analysis Group

D.A. Sharp, Manager Risk Methodology Group

D.J. Baker, Manager Reactor Safety Control Group

P. L. Ames, Manager Computer Technology
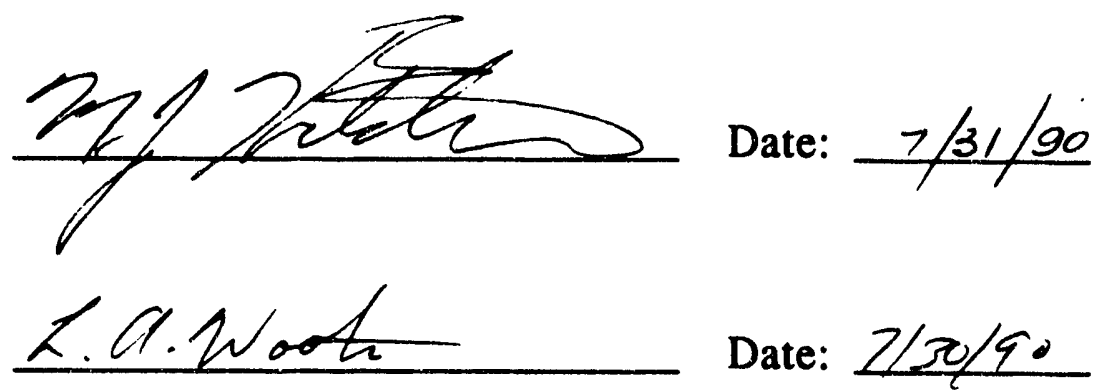

Date: $2 / 30 / 90$

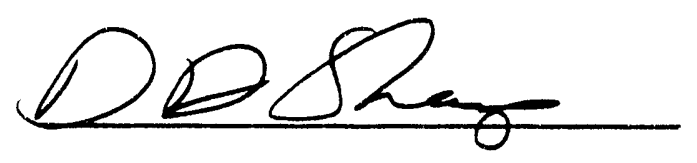

Date: $7 / 31 / 90$

Date: $7 / 24 / 90$

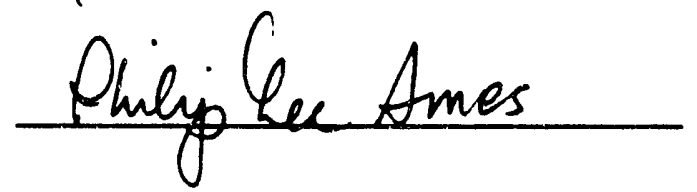

Date: $7 / 31 / 90$ 


\section{CONTENTS}

1.0 SUMMARY

2.0 INTRODUCTION 2

3.0 OBJECTIVES OF PLAN 4

4.0 BASIC ASSUMPTIONS

5.0 LIST OF CODES COVERED

6.0 QA REQUIREMENTS 6

7.0 CONFIGURATION CONTROL ACTION MATRIX 6

8.0 GENERALIZED CONFIGURATION CONTROL PROCEDURE CHECKLIST 11

$\begin{array}{ll}9.0 & \text { USER QUALIFICATIONS }\end{array}$

$\begin{array}{lll}10.0 & R E S O U R C E \\ & 15\end{array}$

$\begin{array}{ll}11.0 & \text { TIME SCHEDULE }\end{array}$

$\begin{array}{ll}12.0 \text { CONCLUSIONS } & 16\end{array}$

$\begin{array}{ll}13.0 & \text { REFERENCES } \\ & 16\end{array}$

$\begin{array}{lr}\text { TABLES } & 17\end{array}$

$\begin{array}{lr}\text { FIGURES } & 19\end{array}$

APPENDIX - GLOSSARY OF TERMS $\quad 22$ 


\subsection{SUMMARY}

A certification plan for computer codes used in Safety Analyses and Probabilistic Risk Assessment (PRA) for the operation of the Savannah River Site (SRS) reactors has been prepared. The plan follows closely the "Certification Plan for Reactor Analysis Computer Codes," WSRC-TR-90-26 (Reference 1) which was deemed to be acceptable by the Savannah River Restart Special Project Office (Reference 2). The present plan fulfills the commitments by Westinghouse Savannah River Company (WSRC) to the Department of Energy Savannah River Office (DOE-SRO) to bring the essential safety related codes under configuration control as required by the "DOE Safety Evaluation Report (Reference 3). Certification as described in Reference 1 covers verification and validation, computer code configuration control, and user qualifications. The plan for verification and validation of the safety and PRA computer codes is contained in Reference 4.

The certification plan is in compliance with the intent of the WSRC quality assurance requirements as contained in Reference 5 and specifically QAP 20-1, "Software Quality Assurance" and the appropriate life cycle procedures derived from QAP 20-1 (Reference 7).

An action matrix, checklists, and a time schedule have been included in the plan. These items identify what is required to achieve certification of the codes.

A list of Safety Analysis and Probabilistic Risk Assessment (SA\&PRA) computer codes covered by the certification plan has been assembled. A description of each of the codes was provided in Reference 4. The action matrix for the configuration control plan identifies code specific requirements that need to be met to achieve the certification plan's objectives. The checklist covers the specific procedures that are required to support the configuration control effort and supplement the software life cycle procedures based on QAP 20-1 (Reference 7).

A qualification checklist for users establishes the minimum prerequisites and training for achieving levels of proficiency in using configuration controlled codes for critical parameter calculations. 


\subsection{INTRODUCTION}

As a consequence of the Department of Energy (DOE) review of SRS reactor operations, WSRC was asked to provide quality assurance for safety related software for technical programs essential to the safety of reactor operation (Reference 3). Safety related software consists of those computer codes used in safety analyses performed in support of the Technical Specifications, Safety Analysis Report, and Probabilistic Risk Assessment. To respond to the DOE request, the certification plan was prepared. The plan addresses safety analysis, severe accident analysis, safety dose assessment, and probabilistic risk assessment computer codes. This plan has also been developed to show compliance and consistency with the comments and suggestions reported in References 2,3 and 6.

The development of the certification plan follows very closely the approach described in WSRC-TR-90-26 (Reference 1). Allowance is made for the fact that there are some differences in software structure and applications between the reactor analysis and the SA\&PRA codes.

The software certification required in Reference 1 consists of three parts as shown in Figure 1. A plan for the verification and validation of existing computer codes was developed in Reference 4 . The remaining slices of the pie in Figure 1, the software configuration plan and user qualification plan, are contained in this document. All three segments of the pie are of equal importance and need to be developed to an equivalent depth to assure the validity of calculated results. Critical results shall be computed by qualified engineers and scientists with verified and validated codes that are properly documented and controlled.

The information flow when configuration controlled computer codes are used by qualified authorized users is illustrated in Figure 2 . There are essentially two main areas of interaction, the user community and the computer technology organization. Both have distinct responsibilities pertaining to the control and use of certified software. In the user community, the cognizant user and the proprietor are the key individuals. The proprietor could also be the owner of the code or a maintainer if the code is controlled by an offsite organization. Computer technology controls the machine related activities of code custodianship. The specific responsibilities of the various organizations are listed below the ovals in Figure 2. The information flow is designated by arrows. The heavier arrows indicate the principal paths of information flow. There exists, on a reduced level, information exchange directly between the cognizant users and the code control custodian. 
Most of the codes covered by this plan have been imported from off-site and have been adapted to solve specific Savannah River Site (SRS) problems. Quality assurance requirements at the various originating organizations may have been different from what is presently required by WSRC. Some of the codes may have been imported and subsequently modified without conforming to established quality assurance practices. A few of the codes have been developed at SRS over a number of years and their evolution may not be in compliance with current QA practices (Reference 5). Other codes are being developed in accordance with current requirements. In all instances, the codes covered by this plan have been used successfully, providing physically and logically reasonable responses, and in some cases replication of experimentally observed results. The plan establishes the means and schedules to develop consistency and eliminate any shortcomings in documented certification of the codes.

The computer codes covered by this plan are those used in performing safety analyses, severe accident analysis, safety related dose assessments, and probabilistic risk assesement in support of the safe operation of the SRS reactors.

Although the computer codes used by WSRC can be grouped into safety and reactor analysis codes, there exist overlaps. Some codes are used by both disciplines. Furthermore, physics or thermal analysis codes provide input to safety analysis. It is important that the reactor analysis codes used be certified to provide the correct input to applications which may be outside their normal range of applications such as input to Safety and PRA analyses.

While "high impact" software (as defined in QAP 20-1 and QAP 3-1 of Reference 5) or software applied to critical parameter evaluations is directly covered by this plan, good engineering practice suggests that applying similar practices to "low impact" software and survey calculations would be prudent. Such compliance would facilitate upgrading the impact level of a code should this become necessary.

The successful implementation of the certification plan requires an understanding of what is meant by code certification, configuration control, and user qualification and the relationship of these terms to the WSRC QA software documentation (Reference 5 and 7 ).

Certification as applied to existing software is the act of determining, verifying, and attesting in writing to the qualification of software used in critical applications. Assurance is provided that the software has been 
properly reviewed and documented for verification, validation, user qralifications, and configuration control. Certified software complies with all applicable requirements in QAP 20-1 in Reference 5.

Verification denotes the process which establishes that the theory is correct, has been properly coded, and that the various code modules are functionally coupled to process information as required.

Validation is the process of establishing how well a computer code meets specific requirements such as reproducing experimental data obtained in special facilities, controlled experiments in operating facilities, operational data, or benchmarks. Benchmarking refers to the process of evaluating the performance of one computer code relative to another code or relative to an exact solution.

Configuration Control is a system to manage and control computer software to provide a certified version of a code for the qualified user. Configuration control prevents unauthorized changes or use of the software coding and establishes a method of handling discrepancies including correction of errors. It also governs retention of supporting documentation such as certification records, user documentation, installation instructions, and benchmark testing results.

User Qualification identifies the minimum levels of proficiency and authorization required for individuals to use certified software for critical application computations.

Additional definitions of words can be found in the glossary of terms found in the appendix.

\subsection{OBJECTIVE OF PLAN}

The objective of the Certification Plan is to establish a documented certification process for the defined set of SA\&RM computer codes listed in this document and their application to Safety Analyses or PRA evaluations as identified in the DOE Safety Evaluation Report (Reference 3) and required by WSRC QA documentation QAP 20-1 (Reference 5) and the software quality assurance life cycle procedures (Reference 7 ).

The main points addressed by the plan are

- Action Matrix for configuration control of high-impact and 
critical application codes

- Specific configuration control procedures

o User certification

\subsection{BASIC ASSUMPTIONS}

Most of the codes covered by the certification plan have been developed by off site organizations. Some codes were developed on site, and still others are being developed in conformance to present day quality assurance requirements. It is believed that codes that have been used on site for a number of years and some other well accepted analysis tools developed off site have been successful in predicting observed results and characteristic trends. A large amount of the required input for certification or more specific configuration control may be in existence. The pertinent information has to be identified and put into the proper documentation and under the required procedural controls.

Following the publication of the certification plan, an assessment phase will establish for each specific code where the deficiencies relative to configuration control are and identify the effort required to implement configuration control.

\subsection{LIST OF CODES COVERED}

A list of pertinent safety analysis, severe accident analysis, dose assessment, and probabilistic risk assessment codes has been assembled. The covered codes are:

$\begin{array}{cccc}\begin{array}{c}\text { Safety } \\ \text { Analysis }\end{array} & \begin{array}{c}\text { Severe } \\ \text { Accident } \\ \text { Analysis }\end{array} & \begin{array}{c}\text { Dose } \\ \text { Assessment }\end{array} & \begin{array}{c}\text { Probabilistic } \\ \text { Risk } \\ \text { Assessment }\end{array} \\ \text { AA3* } & \text { MELCOR } & \text { AXAIR* } & \text { EVNTREE } \\ \text { MARY* } & \text { SCDAP/RELAP5 } & \text { NRC 145/2* } & \text { LHS } \\ \text { PIPEFLOW } & & & \text { PREP } \\ \text { ULTRASIM } & & & \text { SETS } \\ & & & \text { TEMAC }\end{array}$

*High impact software as defined by QAP 20-1

Code descriptions for the above listed codes are contained in Reference 4. 


\subsection{QA REQUIREMENTS}

This document, the Certification Plan for Safety and PRA codes, in conjunction with Verification and Validation Plan for Safety and PRA codes (Reference 4), is designed to satisfy the requirements for software quality assurance as described in the Quality Assurance Manual, 1Q, in particular sections of QAP 2-3, Control of Research and Development Activities, QAP 17-1, Quality Assurance Records Management, and QAP 20-1, Software Quality Assurance pertinent to software quality assurance. To complement this plan, SA\&RM QA procedure is being drafted to implement the appropriate QA requirements (Reference 7).

In addition, Reference 6 identifies a number of particular areas where QAP 20-1 does not fully meet industry standards pertaining to configuration control, software evaluation.and independent verification and validation. The Certification Plan and the software life cycle procedures in Reference 7 address these areas.

\subsection{ACTION MATRIX CONFIGURATION CONTROL}

An action matrix for achieving configuration control has been developed and is shown in Figure 3. The matrix identifies the different types of activities that need to be completed. The matrix serves as a useful tracking mechanism for monitoring the completion of tasks. In the matrix, the names of the various codes are listed, as well as a series of action items required under configuration control. The activities are grouped by topics. The first group covers activities in the user community. The topics in the second group pertain to activities in the computer technology organization and user community. The last category deals with the completion process for configuration control.

Not all the boxes are relevant for each computer code. For example, special shell scripts may be required for only a few codes with the others using a standard script. Consequently, there are several ways for each box to be completed and checked off, by performing the special tasks identified for each box, by referencing why a general situation is applicable for the particular code or by explaining why the box is not applicable to the specific code. In every case, this information is to be included in the documentation for the particular box. 
The following sections give a detailed description of what is required for the specific action items.

\subsection{CODE PROPRIETORS}

Has a code proprietor been identified for a specific code?

A technically knowledgeable person should be assigned to each computer code. This individual would be a member of the user community. The code proprietor would be an experienced individual very familiar with the specific computer code. The person must be able to perform the functions explained under the proprietor responsibilities, as well as meet the qualifications described in the user qualification sections. The proprietor should be intimately familiar with software quality control requirements and procedures. Considerations should be given for identifying a backup proprietor to ensure continuity of code related expertise.

\subsection{PROPRIETOR'S CODE LOG BOOK}

Has a proprietor's code log book been established for each computer code?

The proprietor for each specific computer code should have a notebook dedicated to each specific code in which an ongoing history of code development, alterations, and error corrections is maintained. Such a notebook would focus on the technical aspects of the code rather than the response of the code to system or computer configuration changes. The latter responses are recorded as a part of 7.8, Controlled Tracking System.

\subsection{COGNIZANT USER QUALIFICATIONS}

Are user qualifications in place for using a specific controlled code?

It is recommended that only cognizant users use the controlled codes for critical parameter computations. The general qualification requirements for users are covered in Section 9.0, User Qualifications.

\subsection{USER MANUAL AVAILABILITY}

Where is the User Manual located and how would a user obtain updated instructions?

User Manual preparation is required as a part of the Verification and Validation Plan. It is important for the user to know where to obtain the 
current updated User Manual. This implies that the code user should be assured that the central document repository has an updated User Manual. If this is not the case, then the user needs to be informed where the most recent changes are documented and where assistance in their interpretation can be obtained. A Code Proprietor would have more recent information than contained in the latest User Manual. Sources other than manuals such as special video tapes or computerized tutorials supplementing User Manuals need to be identified. If the User Manuals are prepared by an outside organization, it is the proprietor's responsibility that all the latest changes are communicated to him.

\subsection{TRAINING PACKAGE}

Is a training package in place for using a specific code?

The complexity of the code will dictate the amount of training needed for the use of a specific code. The training package could consist of menu driven familiarization programs, a section in the User Manual with special sample problems, presentations by trainers, special video tapes, or special courses. For each code, the required materials need to be identified, assembled, and supplied to the training function. Training for the users and proprietors should emphasize quality assurance requirements.

\subsection{CODE SOURCE LISTING LOCATIONS}

Has the location of controlled code listing been identified?

The users and proprietor should have access to code listings either as a hardcopy or as a protected computer file that cannot be readily modified. Therefore, the location of such information should be identified for each of the codes. For proprietary codes, a source listing may exist only at the originating organization.

\subsection{TEST PROBLEM AND RESULTS}

Has the location of test problems and test results been identified?

A set of test problems for each of the codes will be developed under the Verification and Validation Plan. The user community should be aware of where to find an updated set of test problems and also the testing records for each of the codes for current and archived versions.

\subsection{CONTROLLED TRACKING SYSTEM}


Has a controlled tracking system been established for each of the codes?

An electronic or hard copy system should be in place for each code such that a record of the coding changes, observed impact of system changes, and error corrections are available to the user community.

\subsection{SYSTEM DEPENDENT CODE DOCUMENTATION}

Is the system dependent code documentation in place?

Computer codes vary in complexity. They may also be processed on different machines and with different operating systems. Documentation should to be in place that informs the user of what machines the code can be processed on, where the required databases are, and what are the specific controls required to access them. Information not included in the User Manual would be included in separate documentation.

\subsection{CODE INTERAC TIVIS}

Have the code interaction impacts been identified?

Some of the computer codes are interrelated. Changes made to one code can impact the results of another code. Documentation should be in place for each code identifying if it is part of an interrelated code system; if so, the relationships and interactions should be described. The potential impact on the system of codes of changing an individual code should be identified. Some of this information would be included in the User Manual.

\subsection{RANGE OF APPLICABILITY}

Has the range of applicability for critical parameter computations of a particular code been identified?

Each code is used for identified specific purposes as described in the software requirement specification developed as a part of the in the SA\&RM QA Implementing Procedures. The V\&V process establishes assurance that the code will compute critical parameters within known limits. Alterations to a code, to the system, or other configuration changes could modify the established range of applicability of a code. Therefore, this range should be carefully spelled out in the criteria for the controlled version of the code and reevaluated upon subsequent alterations. This information will be contained in the Verification and Validation Documentation. 


\subsection{BACKUP VERSIONS}

Are backup versions of the code in place?

It is anticipated, due to the multiplicity of machines in use, that the same version of a code will reside on different machines and thereby provide backup. The same code version may also reside at alternate sites as part of disaster recovery arrangements. Documentation needs to be in place identifying where the codes reside, where backup versions are located, and how upgrading and code maintenance can be performed uniformly and consistently for all code locations.

\subsection{SHELL SCRIPTS AND BANNERS}

Have shell scripts and banners been developed for the codes?

Shell scripts and banners, or page headings, are very useful identifiers for assuring that computations are being performed with controlled versions of the code and for documenting the specific dates of the computation. Shell scripts can also provide users with pertinent control and operation information. It is conceivable that details of shell scripts could contain code specific information or controls. Code specific information pertaining to individual shell scripts should be documented in the User Manual.

\subsection{CONFIGURATION REVIEW}

Has a code configuration control review been conipleted?

Every code should be passed through a technical review to establish if configuration control is in place and to declare that the code is ready for critical computations. A technical review group will be established composed of WSRC Computer Technology and user community personnel with support from consultants. The review will be conducted in accordance with accepted WSRC QA requirements, Reference 5. A report generated by this group would recommend to management for the acceptance of configuration control for a particular code.

\subsection{CONFIGURATION CONTROL IN PLACE}

Is computer code configuration control in place?

Following the technical review group recommendation, configuration control 
of a particular code is accepted by the management of the specific user and Computer Technology organizations. A report by the appropriate managers will satisfy the Department of Energy Savannah River Office of the completion of this activity.

\subsection{GENERALIZED CONFIGURATION CONTROL PROCEDURE CHECKLIST}

In addition to the code specific action matrix, a series of generalized procedures will have to be written and implemented to govern the configuration control process. The suggested generalized procedures with an explanation of their scope are described below. The complacen of a draft of the procedure and the implementation of the approved procedure would be tracked.

Configuration control will require a joint effort between SA\&RM and Computer Technology. The Organizational dependence independence of the elements involved in configuration control must be clearly defined and acceptable to both groups.

The following procedures will most likely be Computer Technology procedures applicable to SA\&RM computer codes and will complemerit procedures established in Reference 7.

\subsection{MOVING A CODE INTO CONFIGURATION CONTROL}

After a computer code has gone through the development stage, a verified and validated version should be submitted for placement under configuration control. This procedure covers the process and what constitutes configuration control.

\subsection{OPERATING UNDER CONFIGURATION CONTROL}

The procedure covers the process of how a user would use a computer code that is under configuration control for a critical calculation. It should allow for the use of proprietary codes. These procedures need to establish who has authorized access to codes and how this authority is controlled. The procedures in Reference 7 provide useful insight.

\subsection{CHANGES THAT PROPRIETORS MAKE}

The procedure covers the steps that need to be taken with respect to controlled codes when the code proprietor makes changes. 


\subsection{CHANGES IN COMPUTER ENVIRONMENT}

The procedure covers the steps that need to be taken with respect to controlled codes when changes in the computing environment are made, particularly in the operating system area.

\subsection{ARCHIVING RESPONSIBILITIES AND BACKUP DISASTER CONTROL}

The procedure covers the archiving of controlled software and test problems associated with testing the codes. The scope would address how multiple versions of the code are archived and how disaster control backup versions are maintained.

\subsection{RETIRED CODES}

The procedure addresses how and when to retire a code, what records to keep on retired codes, and how to retrieve the information in the future.

\subsection{TRACKING OF CONFIGURATION CONTROL DOCUMENTATION}

The procedure covers what documentation on controlled codes should be tracked, how it is to be tracked, and what documentation needs to be generated.

\subsection{ERROR IDENTIFICATION AND CORRECTION PROCEDURES}

The procedure describes the process of of how an error discovered by a user is corrected including making corrections to the controlled version of the code. The procedure should cover verification testing.

\subsection{GENERALIZED TRAINING REQUIREMENTS FOR USERS AND SYSTEM OPERATORS}

The procedure addresses generalized training for users and system operators in the operation and maintenance of configuration controlled codes.

\subsection{PERIODIC CODE TESTING WITH TEST PROBLEMS}

The procedure establishes periodic testing requirements for controlled codes. 


\subsection{USE OF WORK STATIONS AND PCS IN CRITICAL CALCULATIONS}

A procedure will cover the handling of configuration control for work stations and personal computers should such devices be used for high impact software and to compute critical parameters. The procedure should consider pertinent sections of "Control of PC-Based Analytical Software" in Reference 8.

\subsection{USER QUALIFICATIONS}

\subsection{USER LEVEL DESCRIPTION}

As a part of the third segment of the certification plan, user qualification requirements are considered. Within the user community, there may be three levels of proficiency relative to the use of configuration controlled computer codes for critical calculations: Apprentice User; Cognizant User; and Code Proprietor. The use of the Apprentice level is optional for a particular code as determined by management. The designation of an individual as an Apprentice or Cognizant User is the responsibility of the appropriate management. All levels of users require specialized training in software quality assurance principles and compliance with specialized procedures. While the users will most likely belong to the software owner's organization, this is not a requirement. Qualified individuals in other WSRC organizations can perform calculations using certified SA\&RM codes.

\subsubsection{The apprentice user}

The apprentice user is a person who is in training to use the code and would work under the tutelage of a cognizant user or proprietor. This individual generally is in the process of learning to understand the purpose of the code calculations, to follow the input logic and selection of certain variables, and pick out specific results from the output.

The apprentice user may have a significant understanding of the physical processes being evaluated by the code, but individual code systems may have their own input peculiarities which require specific code familiarity to avoid incorrect results. The apprentice user may perform independent non critical analyses, but input and output should still be checked by a more experienced cognizant user. The apprentice user does not perform critical 
parameter analyses.

\subsubsection{The cognizant user}

The cognizant user is someone with experience in executing the computer code. The individual has been designated by management as a cognizant user. As such, the person understands the purpose of the code and is familiar with the code's input requirements and output. A cognizant user is aware of the quality assurance requirements for documenting computer calculations required for critical applications and is qualified to perform such analyses.

The cognizant user is sufficiently familiar with the code input and output to perform independent analyses, but may not possess sufficient understanding of the software coding to make changes to the code. The user should be familiar enough with the code to identify when it is not functioning properly. The individual notifies the code proprietor of any possible error conditions and requests the proprietor to make any necessary changes.

\subsubsection{The code proprietor}

The code proprietor has an in-depth understanding of the software's coding structure and how the code works. The individual has been designated by management as a code proprietor. Each computer code has its own code proprietor. The code proprietor shall understand the logical flow of the code and the numerical methods used by the code, both with respect to theory and range of applicability. The person is sufficiently familiar with the code to make coding changes, verify the programming, and validate the code against example problems. The code proprietor is aware of the quality assurance requirements for contiguration control, verification, and validation. The code proprietor maintains a notebook in which code evolution is tracked. Changes to the cor and the impact of these changes are recorded. This individual maintains a record of validations and performs necessary validations following alternations to the code. The code proprietor is considered to be a cognizant user. There should be only one code proprietor for each computer code with a trained backup person identified.

\subsection{MINIMUM REQUIREMIENTS FOR USER LEVELS}

There are certain minimum standards which are required for an engineer or scientist to reliably perform computer code calculations in a technical field. 
These minimum requirements will help to ensure that the person has an adequate technical background for the various levels of user qualification. The User Qualification And Function Checklist contains guidelines as to user training and proficiency needed to become qualified for the various user categories

\subsection{USER QUALIFICATION AND FUNCTION CHECKLIST}

Some of the requirements listed in the User Qualification And Function Checklist should be considered as guidelines, and not as absolutes. Decisions of this nature should be left to the discretion of their immediate management. For example, a highly competent engineer who is capable of learning new concepts at a faster pace than most others should not be limited to a full year of work experience before being allowed to work independently, especially if he has a significant academic background in the field he is currently working in. Designation of individuals to the various user levels should be documented by management.

\subsection{ADDITIONAL TRAINING}

In order to instruct people in the use of a particular code, it may be beneficial to provide special training seminars on the computer code's numerical methods and practical use. Course material for such a seminar would include numerical sample inputs for a variety of problems normally solved by the code, and would cover many of the different capabilities of the code systems.

Training seminars (when available) would be invaluable to apprentice users, in giving them a "steeper" learning curve, and could also help cognizant users gain an improved understanding. These training seminars and workshops could be taught by the code proprietor or other experts such as the designers or owners of the code.

\subsection{RESOURCE REQUIREMENTS}

The resource requirements will be established as the second phase of the certification effort. After publication of the plan, an assessment will be made for each code to determine the extent of certification materials in place and what is missing. Based on the assessment report, resource allocations and more realistic time schedule for each code will be established to achieve certification compliance. 


\subsection{TIME SCHEDULE}

The time schedule for completion of the certification process for the Safety and PRA codes requires that the verification and validation be in place, the codes are under configuration control, and the users of the codes have been qualified. Proposed individual milestones for configuration control and user qualification are listed in Table 2.

\subsection{CONCLUSIONS}

A Plan has been established that brings certain computer codes used for safety analysis and PRA evaluation of SRS reactor operations into compliance with certification requirements as established by WSRC QA requirements.

\subsection{REFERENCES}

1. H. Toffer, R. D. Crowe, K. N. Schwinkendorf (WHC) and R. E. Pevey (WSRC), WSRC-TR-90-26, "Certification Plan for Reactor Analysis Computer Codes (U), January 1990.

2. Letter, "Certification Plan for Reactor Analysis Computer Codes," WSRCTR-90-26, F. R. McCoy to J. L. Gallagher, March 23, 1990.

3. DOE Safety Evaluation Report, Section 5.8, "Verification of Computer Codes, Rev. 0," March 15, 1990.

4. R. D. Crowe, H. Toffer, (WHC) and M. J. Ades (WSRC), WSRC-RP-90-433 "/erification and Validation Plan for Safety and PRA Codes," May 1990.

5. 1Q, "Quality Assurance Manual," April 1, 1990.

6. S. B. Ailes, A. C. Spencer, and D. A. Bevard, "Reactor Restart Software Quality Assurance Assessment Final Report," May 3, 1990.

7. 1Q-35, "SA\&RM Quality Assurance Procedures".

8. WSRC Safety Analysis Group Technical Procedure "Control of PC-Based Analytical Software", WSRC-TM-90-6, April 20, 1990 
Table 1

USER QUALIFICATION AND FUNCTION CHECKLIST
Apprentice
Cognizant
Proprietor

Formal Education in

Relevant Discipline

$\mathbf{X}$

$\mathbf{X}$

$\mathrm{X}$

Completed Code Training

$\mathbf{X}$

$\mathbf{X}$

$\mathrm{X}$

Familiar with Technical Area of Computation

$\mathbf{X}$

$\mathbf{X}$

$\mathrm{X}$

Software QA Requirements

Training

$\mathbf{X}$

$\mathbf{X}$

$\mathrm{X}$

Minimum Experience (one year)

$\mathbf{X}$

$\mathrm{X}$

Performs and Reviews

Critical Calculations

$\mathbf{X}$

$\mathbf{X}$

Performs Required Code

Alterations

$\mathrm{X}$

Maintains Code Documentation

$\mathrm{X}$

These qualifications should be considered as guidelines. Assignment of levels to the users remains a management determination and requires backup documentation. 


\section{Table 2. Configuration Control and User Qualification Proposed Activity Milestones}

\section{Milestones}

A. Matrix Responsibilities Defined and code proprietors Established

May 31,1990

B. Code Proprietor Logbooks Established

August 31,1990

C. User Qualification System in Place

October 30, 1990

D. Draft of the Configuration Control Procedures Completed

November 30, 1990

E. User Manuals in Place

December 30, 1990

F. User Qualification Completed

January 15,1991

G. Generalized Configuration Control

Procedures in Place

January 30,1991

H. Training Packages for Codes

Established

February 28, 1991

I. Configuration Control Action Matrix Completed

May 30, 1991

J. Configuration Control Review Comments Resolved

September 30, 1991 


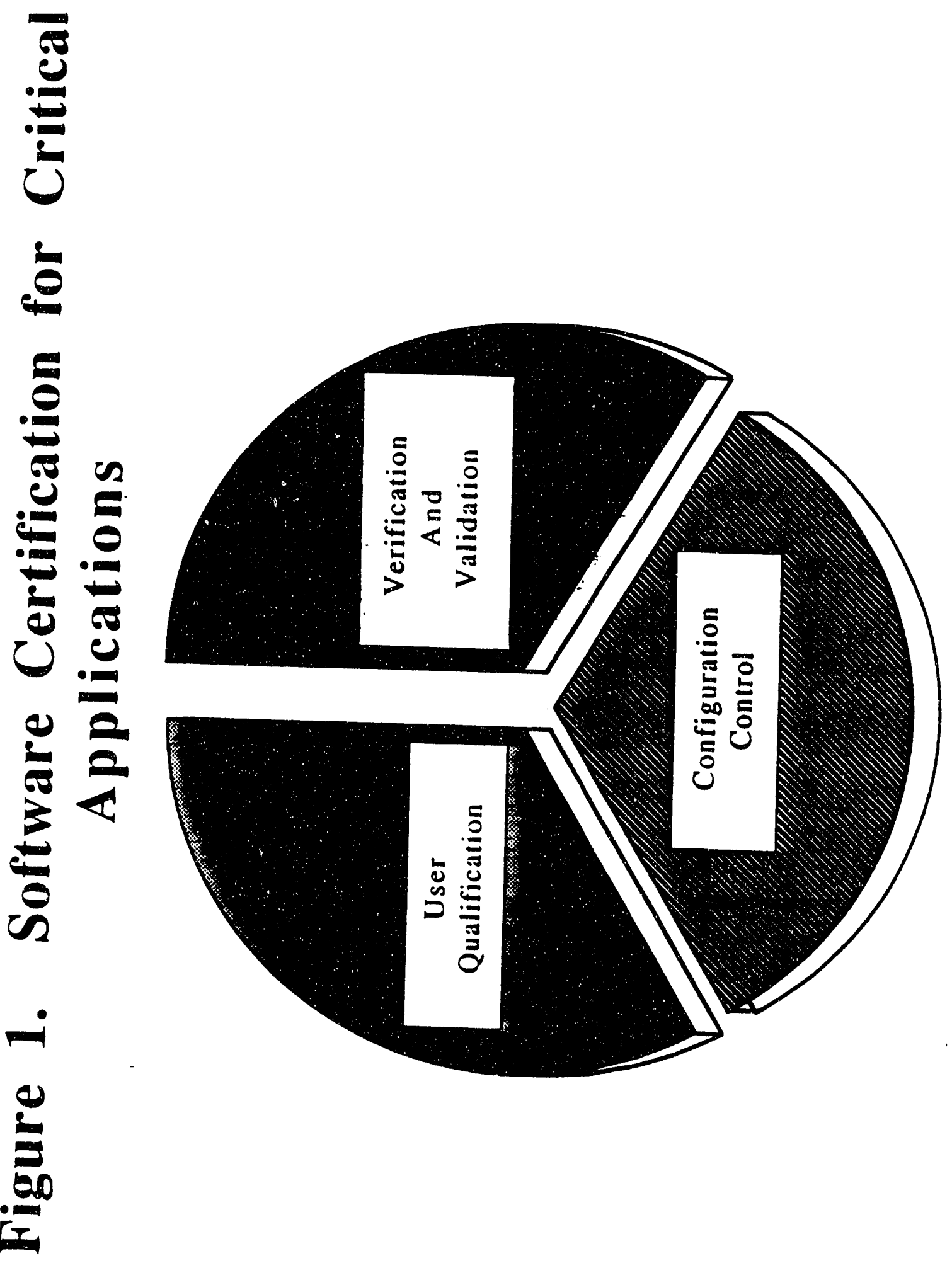




\section{Figure 2 Certification Plan Information Flow}

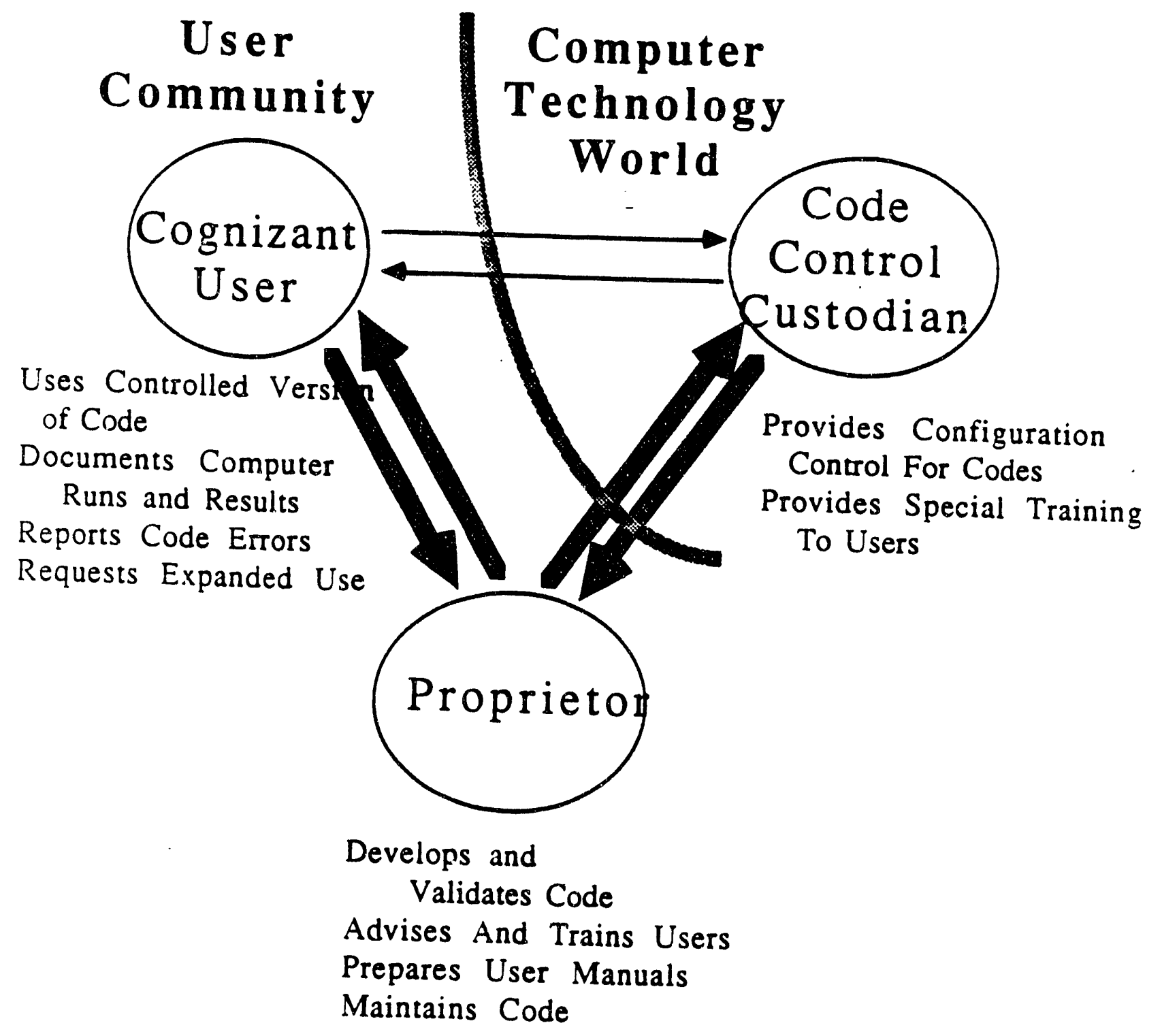




\section{Figure 3. \\ Configuration \\ Control \\ Action Matrix}

Safety Analysis

\begin{tabular}{|c|c|c|}
\hline $\begin{array}{l}\text { AA3 } \\
\text { AXAIR } \\
\text { MARY } \\
\text { MECOR } \\
\text { NRC 145/2 } \\
\text { PIPEFLOW } \\
\text { SCDAP/RELAP5 } \\
\text { ULTRASIM }\end{array}$ & 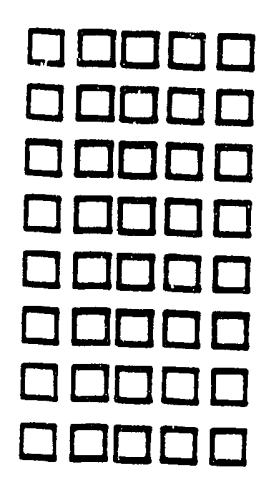 & 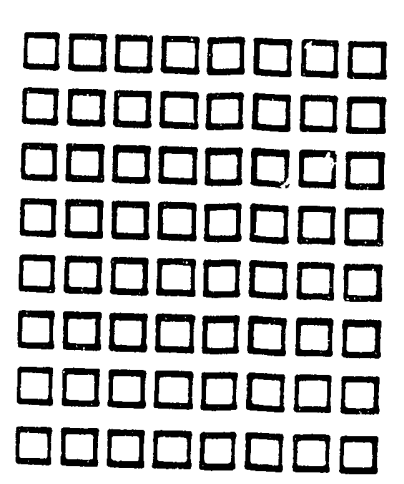 \\
\hline
\end{tabular}

PRA

EVNTRE
UHS
PREP
SETS
TEMAC

\begin{tabular}{|c|c|}
\hline 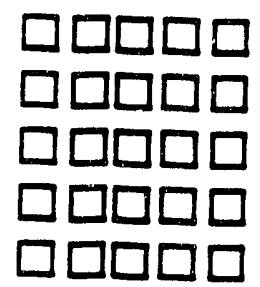 & 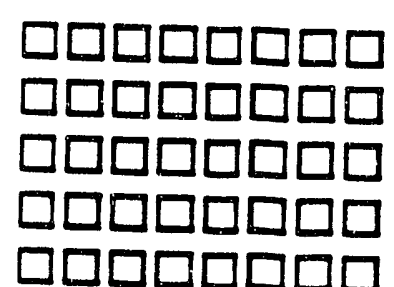 \\
\hline
\end{tabular}




\section{APPENDIX}

\section{Glossary of Terms}

The following definitions are given to provide a comnion understanding of terms as used in this plan and other WSRC documents.

benchmarking. The process of validation performed by evaluating the performance of one computer code relative to another code or relative to an exact solution.

certification. As applied to existing software, is the act of determining, verifying, and attesting in writing to the qualification of software used in critical applications. Assurance is provided that the software has been properly reviewed and documented for verification, validation, user qualifications, and configuration control.

code control custodian. The person or persons in Computer Technology responsible for performing the required code configuration management for the identified codes.

code proprietor. A user identified for each code and usually in the owner organization, responsible for the making code alterations, advising other users and interfacing with code control custodian.

configuration control. A system to manage and control computer software to provide a certified version of a code for the qualified user. Configuration control prevents unauthorized changes or use of the software coding and establishes a mechod of handling discrepancies including correction of errors. It also governs retention of supporting documentation such as certification reccrds, user documentation, installation instructions, and benchmark testing results.

designer. The person, or persons who produce the product for the owner. The owner and designer may both be members of SA\&RM or the designer may be another organization either within or outside WSRC.

existing software. All software used within SA\&RM that was in use or in development prior to the effective data of the initial issue of the SA\&RM QA procedure 1.13 is considered as existing software.

life cycle phase. The period of time during the software development or operation that can be characterized by a primary type of activity. The 
software life cycles include a requirements phase, a design phase, and implementation phase, an installation phase and checkout phase, an operation and maintenance phase and a retirement phase.(such as design and testing) that is being conducted. These phases may overlap one another. For V\&V purposes, no phase is concluded until it development products are fully verified.

owner/ owner organization. The person, or persons either within SA\&RM or outside responsible for the defining or identifying the particular software product, for describing the needs, functional requirements, and constraints and for providing verifiable criteria for accepting or rejecting the software product.

software requirements specification. Documentation of the essential requirements ( functions, performance, design constraints, and attributes) of the software and its interfaces.

system software. Software designed for a specific computer or a family of computer systems to facilitate the operation and maintenance of the computer system and associated programs, for example operating systems, compilers utilities.

testing. An element of the validation process to determine the capability of an item to meet specified requirements. The process of analyzing software should detect the differences between existing and required conditions (that is, bugs) and evaluate the features of the software item.

test plan. A document describing the approach to be taken for intended testing activities. The plan typically identifies the items to be tested, the testing to be performed, test sequences, personnel requirements, and evaluation criteria.

test procedure. A document specifying a sequence of actions for executing a test.

users. The person, or persons, who actually operate or interact directly with the software program. The user(s) and owners will often be the same persons, but this is not necessary. Three levels of users have been identified based on user experience, education and ability in the SA\&RM certification plan (apprentice user, cognizant user and code proprietor).

user qualification. Identifies the minimum levels of proficiency and authorization required for individuals to use certified software for critical 
application computations.

verification. The process of establishing that the theory is correct and has been properly coded and that the various code modules are functionally coupled to process information as required.

validation. The process of establishing how well a computer code meets specified requirements such as reproducing experimental data obtained from special facilities or from controlled experiments in operating facilities, from normal operation or from benchmarking activities. 

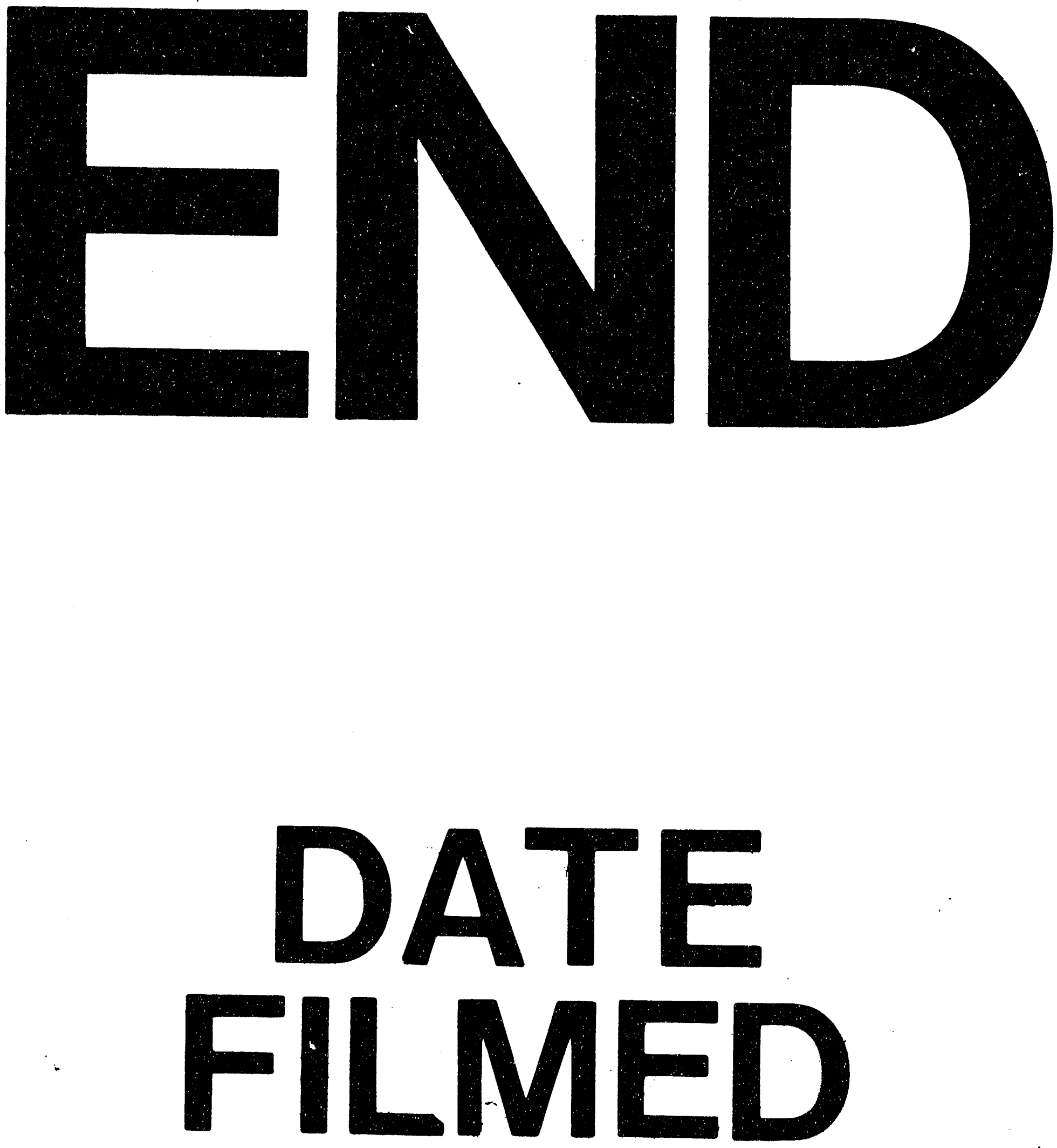

$$
4120 / 93
$$


